\title{
A Novel Method for Ion Track Counting in Polycarbonate Detector
}

\author{
Gholam Hossein Roshani, ${ }^{1}$ Sobhan Roshani, ${ }^{2}$ Farzin Shama, \\ Saeed Roshani, ${ }^{2,3}$ and Mohammad Mahdi Roshani ${ }^{2}$ \\ ${ }^{1}$ Kermanshah University of Technology, Kermanshah 6717863766, Iran \\ ${ }^{2}$ Razi University, Kermanshah 6714967346, Iran \\ ${ }^{3}$ Department of Electrical Engineering, Kermanshah Branch, Islamic Azad University, \\ Kermanshah 6718997551, Iran
}

Correspondence should be addressed to Sobhan Roshani; sobhan_roshany@yahoo.ca

Received 18 August 2013; Accepted 13 November 2013

Academic Editors: H. Lu and C. Quan

Copyright (C) 2013 Gholam Hossein Roshani et al. This is an open access article distributed under the Creative Commons Attribution License, which permits unrestricted use, distribution, and reproduction in any medium, provided the original work is properly cited.

A computer program for recognizing and counting the track of ions that are detected with polycarbonate detector has been written using MATLAB software. There are different programs for counting the track of ions in different detectors. Algorithm of this program specially has been written for polycarbonate detector and also for low magnification of optical microscope. Thus, with this method as per image of optical microscope, greater numbers of ions are visible and general distribution of ions can be better known. However, the accuracy of counting program is very high.

\section{Introduction}

Polycarbonate is one of the detectors that is used in solidstate electrochemical etching detection method. When ions strike with polycarbonate detector, tracks are generated in detector. After several hours of etching in special solution and applying high voltage to polycarbonate, ion tracks can be seen with unaided eyes. This detection method has been being used for more than three decades by Sohrabi et al. [1-5]. After etching detector and applying high voltage to etching chamber, ion tracks must be counted and locally determined. A picture is taken from tracks, using optical microscope and CCD camera that is connected to computer. This picture is read by the proposed algorithm, and then the number of ion tracks is counted and locally determined with high accuracy. A different magnification is used for seeing the tracks. Our optical microscope has three magnification degrees: ten times, forty times, and hundred times. The goal is counting the total number of ions; therefore, if the image magnification is low, then more ion tracks can be seen in the picture and distribution will be shown better. For this reason, program algorithm is written for picture with low magnification and also it has high accuracy.

\section{Algorithm of New Method}

A variety of methods for counting ion tracks in different detectors have been proposed so far [6-9]. The presented program in this study is written specially for the polycarbonate detector and also for low magnification. Comparison is done between pixels and this procedure continues in the whole of the picture. Using this algorithm, all of the tracks are determined and the coordinates of them are specified. Pictures of ion tracks in polycarbonate detector with high magnification are shown in Figure 1. A picture with low magnification is shown in Figure 2.

The algorithm of the program is as follows:

reading the image;

converting image to gray scale: in order to improve the accuracy of counting, image is converted to black and white image;

inverting the image; 

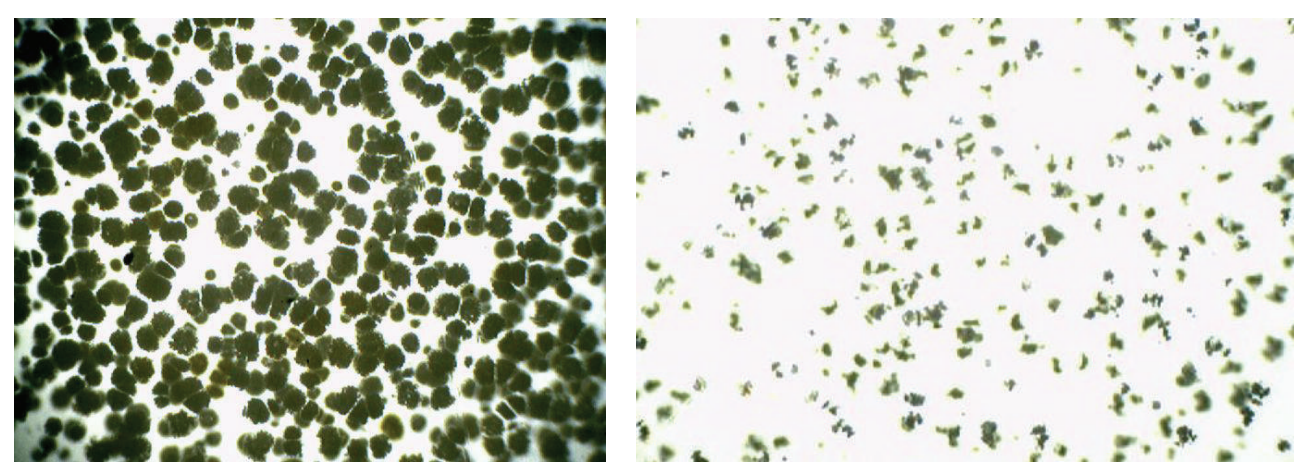

FIgURE 1: Pictures of tracks with high magnification.

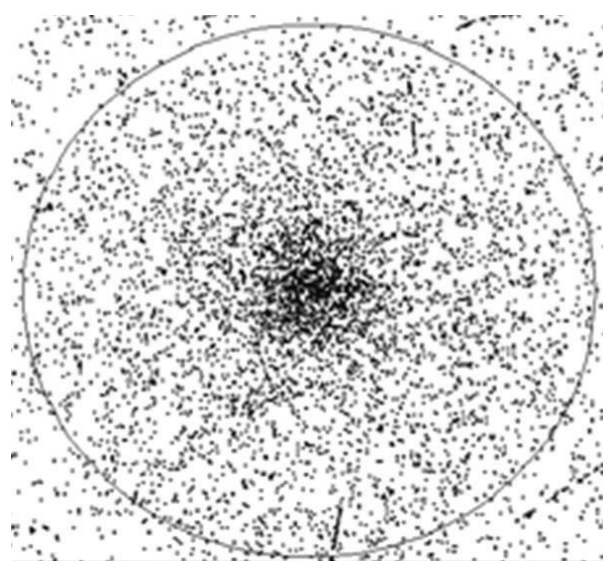

FIgURE 2: Picture of tracks with low magnification.

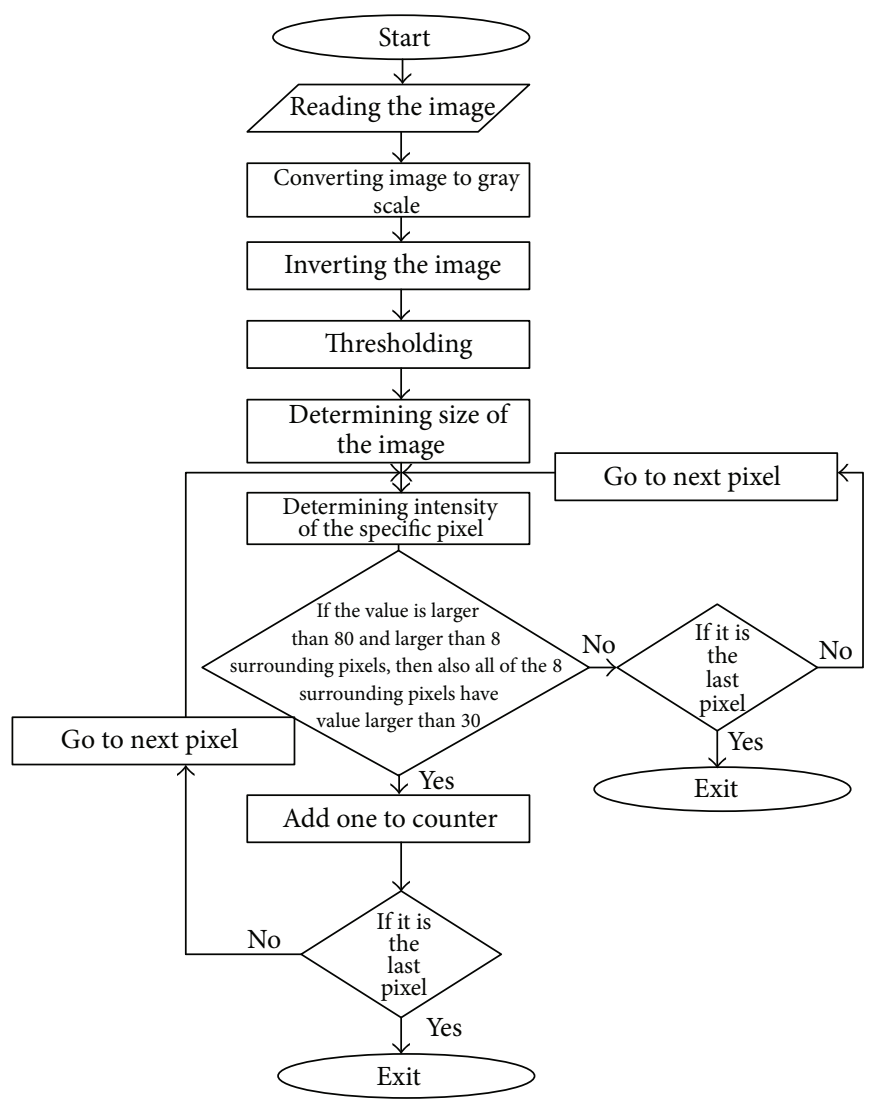

FIGURE 3: Flowchart of program. 


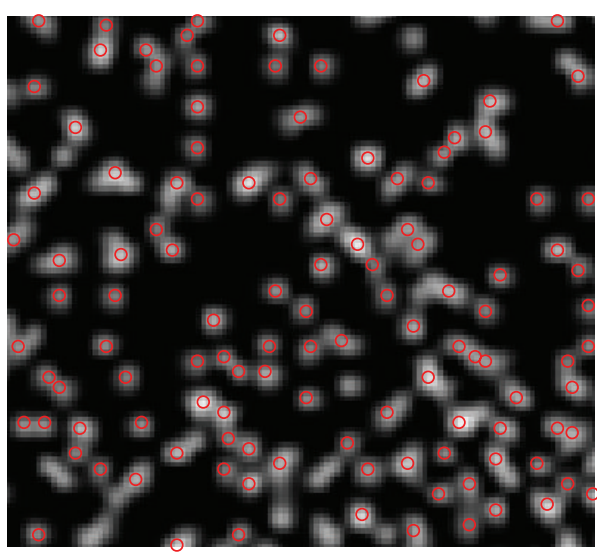

(a)

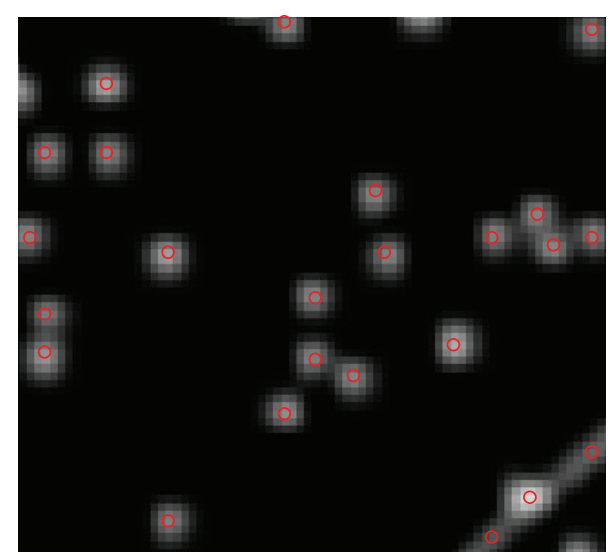

(b)

FIGURE 4: Determination of tracks in the image.

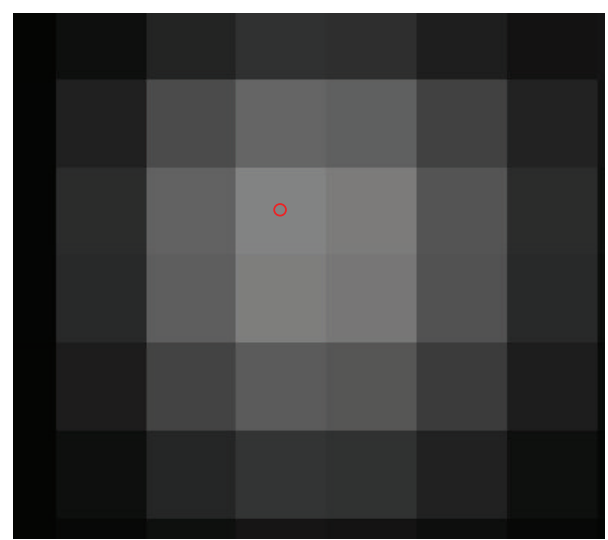

FIGURE 5: A sample pixel of a track.

converting image to binary: after inverting the image, it should convert to binary. At first, threshold level should be determined such that the tracks are perfectly specified. This threshold level has a significant effect on the final counting process;

comparison of pixels: this part is the main and most important part of the program. Program begins from second column and second row and compares the current pixel with surrounding pixels. After comparison, this method is repeated for next pixel. This comparison is done for whole pixels of the picture and finally, number of tracks and local coordinates are determined. The flowchart of program is shown in Figure 3.

According to the algorithm, the comparing method is pixel by pixel in image. With this method, high accuracy in counting has been acquired.

\section{Algorithm Simulation}

The procedure of the proposed algorithm is explained on a sample image in the following.
The tracks are specified in Figure 4 with red circles. All the tracks are found in this sample image. Each pixel in the image is like sample pixel in Figure 5.

\section{Conclusion}

As it is seen from images, the new algorithm, which is based to read low magnification images, has high accuracy. The algorithm has many advantages. For example, more regions and tracks could be investigated and counted.

\section{References}

[1] M. Sohrabi, "A new triplet electrochemical etching (TECE) method," Radiation Protection Dosimetry, vol. 48, no. 3, pp. 279283, 1993.

[2] M. Sohrabi and G. H. Zainali, "A new versatile electrochemical etching chamber (VECEC) system for multi-size and multishape detector processing," Radiation Measurements, vol. 31, no. 1-6, pp. 153-156, 1999.

[3] M. Sohrabi, "A new multi-chamber electrochemical etching system approach for rapid characteristic response studies in polymeric dosemeters," Radiation Protection Dosimetry, vol. 12, no. 1, pp. 55-59, 1985.

[4] M. Sohrabi and M. Sadeghi, "Efficient detection and spectrometry of alphas from radon daughters in polycarbonate," International Journal of Radiation Applications and Instrumentation D, vol. 19, no. 1-4, pp. 421-422, 1991.

[5] M. Sohrabi and A. Mostofizadeh, "Measurement of photoneutron doses in and out of high-energy X-ray beam of a saturne20 medical linear accelerator by ECE polycarbonate detectors," Radiation Measurements, vol. 31, no. 1, pp. 479-482, 1999.

[6] D. L. Patiris, K. Blekas, and K. G. Ioannides, "TRIAC: a code for track measurements using image analysis tools," Nuclear Instruments and Methods in Physics Research B, vol. 244, no. 2, pp. 392-396, 2006.

[7] H. Arias, D. Palacios, L. Sajó-Bohus, and T. Viloria, "Alternative procedure for LR 115 chemical etching and alpha tracks counting," Radiation Measurements, vol. 40, no. 2-6, pp. 357362, 2005. 
[8] G. J. Sykora and M. S. Akselrod, "Novel fluorescent nuclear track detector technology for mixed neutron-gamma fields," Radiation Measurements, vol. 45, no. 3-6, pp. 594-598, 2010.

[9] L. Tsankov, D. Pressyanov, K. Mitev, S. Georgiev, and I. Dimitrova, "Automatic counting of chemically etched tracks by means of a computer scanner," Radiation Measurements, vol. 39, no. 5, pp. 557-559, 2005. 

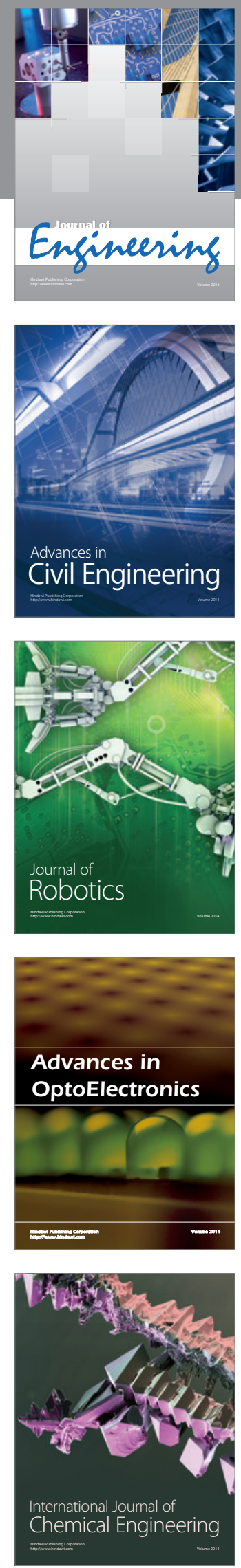

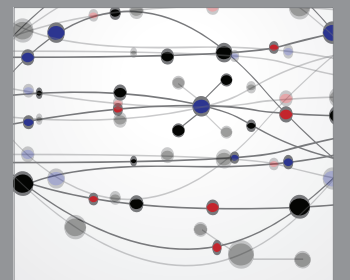

The Scientific World Journal
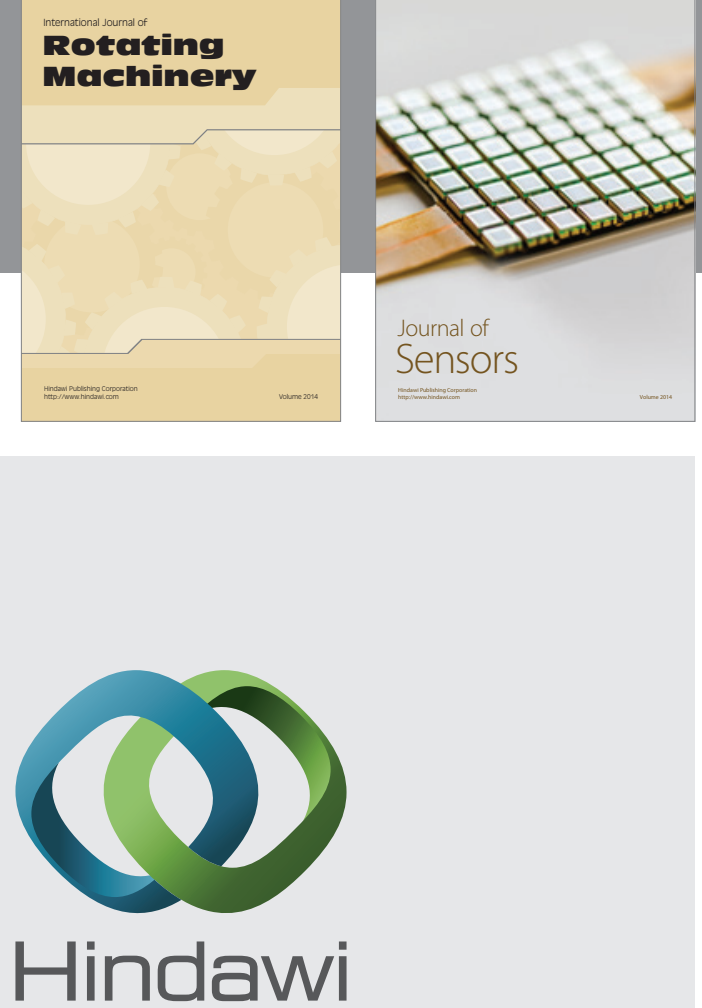

Submit your manuscripts at http://www.hindawi.com
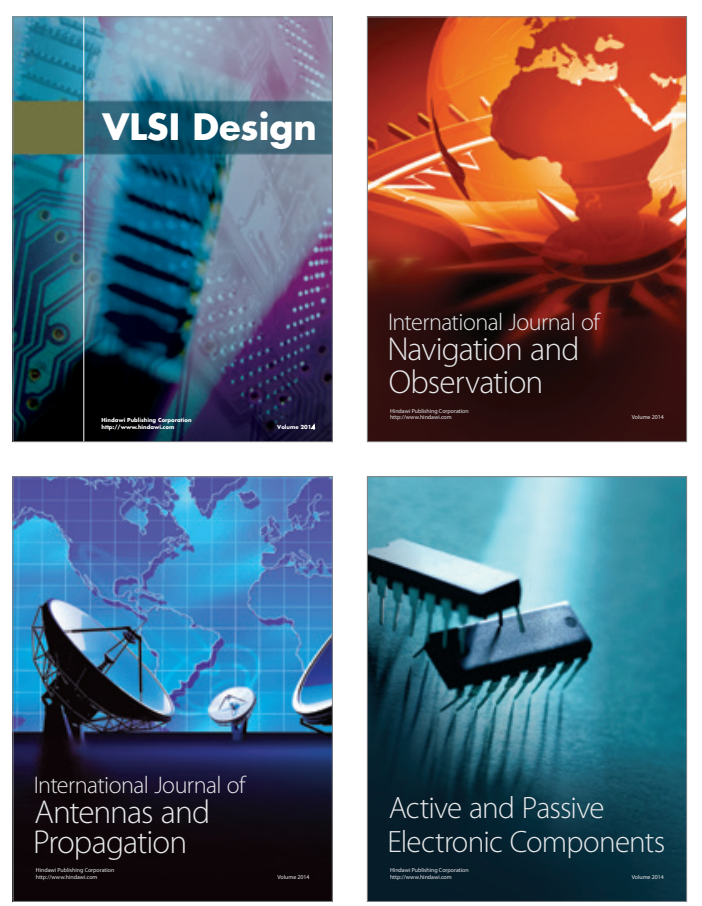
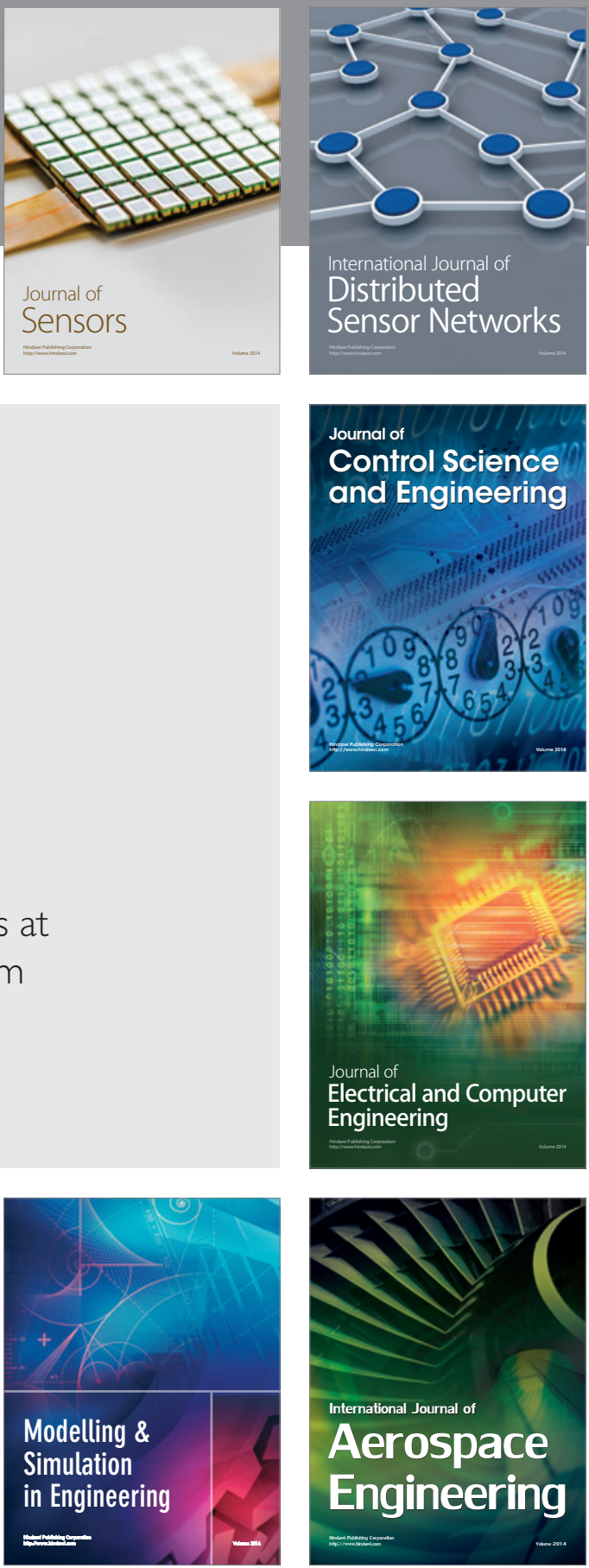

Journal of

Control Science

and Engineering
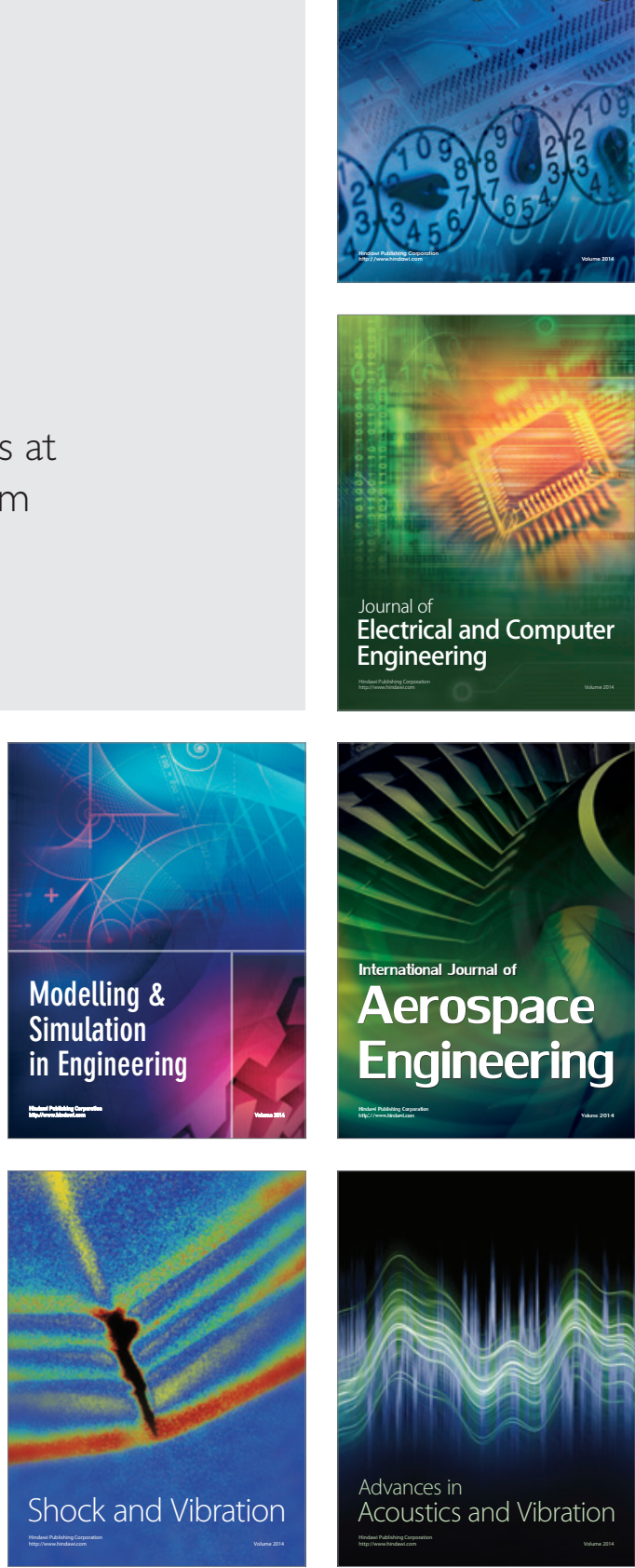